Journal of Engineering and Applied Sciences 14 (12): 4242-4248, 2019

ISSN: 1816-949X

(C) Medwell Journals, 2019

\title{
Design and Implementation of an Interval Type-2 FPIDSM Controller for Magnetic Levitation System
}

\author{
Ahmed A. Oglah \\ Department of Control and Systems Engineering, University of Technology, Baghdad, Iraq
}

\begin{abstract}
This study is basically centered to position control of the steel sphere with no mechanical support. Those interval fuzzy logic controller type-2 like Proportional plus integral plus Derivative of Sliding Mode (IT2FPIDSM) takes idea of an interval fuzzy logic controller type-2 (IT2FL) and the Sliding Mode control (SM) which gets those preferences from claiming both strategies. Those IT2FPIDSM might decline the multifaceted nature of investigation also utilization using the sliding surface which utilization of rule bases. The uncertainty in real time application is associated (oscillation connected) with the accessible information reliable happens and high nonlinearity of system parameters. The system of Magnetic Levitation (ML) tests in different disturbance, tracking signals and robustness state, furthermore, checked for this system with help of proposed controllers. All controller gains are tuned using Social Spider Optimization ( $\mathrm{SSO}$ ). The nominated controller is designed with the classical controller like FL, SM controllers and IT2FPID controller in the MATLAB-Simulink and then applied in real time environment. The simulation and experiment results are presenting that the proposed controller has effective control action.
\end{abstract}

Key words: Magnetic levitation equipment, sliding mode controller, interval type-2 fuzzy logic, MATLAB, control action, simulation

\section{INTRODUCTION}

Magnetic levitation model is exceedingly nonlinear framework furthermore greatly applicable skeleton. ML framework may be utilized to suspending those object or item without whatever mechanical support. To complete this research, electro-magnetic induction must be used. Since, these frameworks have the ability should suspend whatever object over airspace by utilizing sensors for watching position about levitated for controlled sum of electric current to electro-magnet, an object can be fly and stay into air. $\mathrm{ML}$ might a chance to be joined to various requisition regions to example, different fields, for example, frictionless deportments, uncommon quickness magnetic levitation system trains, hovering from claiming wind tunnel models, maglev anti-vibration systems and so on. In $\mathrm{ML}$ system two undesirable parameters uncertainty and high nonlinearity. These are a big problem to control the steel sphere via. the robust controller. The control designer has overcome the matter of adjustment analysis for ML system. type-1 Fuzzy Logic Controller (T1FLC) need been accomplishment completely also comprehensively used in distinctive fields (Zadeh, 1975). The better performance response of system when combined with the Sliding Mode control (SM) orneural network etc. For the class about frameworks will which it applies, sliding mode controller setup provides for an systematic lifestyle should manage those issue for keeping dependent upon dependability also enduring execution notwithstanding demonstrating imprecision. However, controller creator would confronting a couple Hindrances in the SM controller done type for chattering aspects the point when those framework progress may be close to of the sliding surface. Chattering is undesirable, since, it incorporates amazingly secondary control action, chattering must a chance to be decreased (wiped out) to that controller on performing authentically. The FSM controller (Shen and Chang, 2013; Nordin et al., 2013), an mix from claiming FL also SM controller, gives an direct methodology should arrange those controllers deliberately and provides for the absolute stability of the framework. The nominated IT2FPIDSM controller is a blend of IT2FL system and SM control it gets the advantages of both methods which can reduce the number of rules safely. This controller might similarly, provide for all the more heartiness over the IT2FLC to taking care of the precariousness and unsettling influence (Soto et al., 2015). In this research the nominated controller is an IT2FPIDSM controller, based on interval type-2 fuzzy logic. It constrains the plant on taking after the reference model by minimizing the error between the middle of the reference model and genuine plant output. Likewise, we most likely mindful of $\mathrm{Ml}$ system may be profoundly (very) nonlinear framework. We 
Notwithstanding tell those models will be imprecise. Model imprecision might happen from vulnerability regarding plant (change for inductance and imperviousness of electromagnet coil), different outer aggravation, for example, such that light source and sensor correctness. In regards controlling reason for plant exactly demonstrating vulnerability may be present; this might make ordered under two approaches, for example, (unstructured and structured) uncertainties. The conventional type-1 FSM controller introduced in literature as widely spread. Design the FSM controller for cart pole model (Nordin et al., 2013). The robust design of FSM controller as indirect adaptive has been introduced by Mendel et al. (2014), Erguzel (2013) and Corke (2012). The new controller is given for $\mathrm{ML}$ system as Shanmugasundram et al. (2014). The uncertainty problem needed to treat it by type-2 fuzzy logic because the type-1 or classical fuzzy has not able to treat it. For flexible robot manipulator with parameter, uncertainty is designed a type-2 fuzzy set controller (Chaudhary et al., 2014). A little number of papers are accessible for type- $2 \mathrm{SM}$ controller, for example, control of DC-DC converter T2FSM controller. What's more than T2FL controller (Khanesar et al., 2013). Hybrid optimization to design an IT2FSM controller which involves type-2 fuzzy and sliding mode controllers (Soto et al., 2015). This study comprises from six partitions. Those scientific model of the ML system need to be been talked about in part 2, part 3 clarifies those IT2FLS, configuration furthermore execution of the IT2FPIDSM controller may be examined in part 4 at that point simulations need aid performed ahead ML system utilizing MATLAB. On part-5, simulation and results are examined. Furthermore, during last, part 6 draws those conclusions.

\section{MATERIALS AND METHODS}

Magnetic levitation system mathematic model: The ML system is steel sphere levitation system in which a steel sphere will hold on in space air with no mechanical support. As shown in Fig. 1 and $2 \mathrm{ML}$ system involve of steel sphere, sensor light emitting diode source and an electro-magnetic coil. $\mathrm{ML}$ system mathematical equations is according to the electro-dynamics models equations and steel sphere kinematics. In vertical axis movement, newton 2nd law is applied:

$$
\begin{gathered}
f(I, D)+M G=M\left[\frac{d^{2}}{d t^{2}}\right] \\
k_{i}=f_{i}\left(I_{0}, D_{0}\right)=\frac{d f(I, D)}{d I}=\frac{2 k I_{0}}{D_{0}^{2}}
\end{gathered}
$$

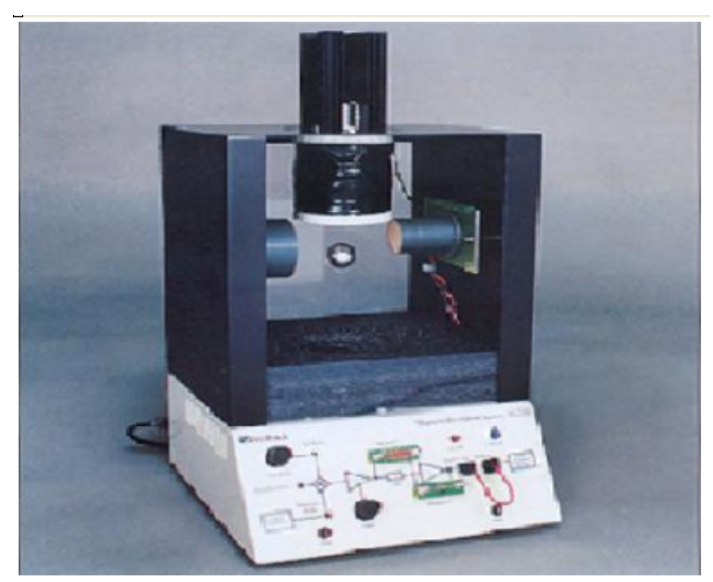

Fig. 1: Magnetic Levitation system (ML)

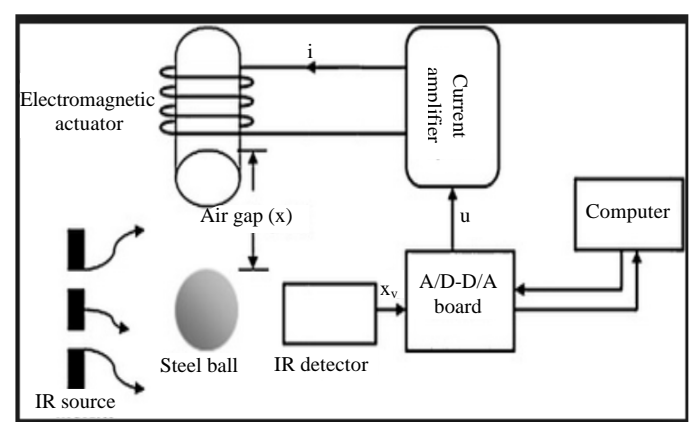

Fig. 2: The schematic form of magnetic levitation system (Sain et al., 2016)

$$
\mathrm{k}_{\mathrm{z}}=\mathrm{f}_{\mathrm{z}}\left(\mathrm{I}_{\mathrm{O}}, \mathrm{D}_{\circ}\right)=\frac{\mathrm{df}(\mathrm{I}, \mathrm{D})}{\mathrm{dx}}=-\frac{2 \mathrm{kI} \mathrm{I}_{\circ}^{2}}{\mathrm{D}_{\circ}^{3}}
$$

where, $k_{\mathrm{i}}$ and $\mathrm{k}_{\mathrm{x}}$ the stiffness coefficient. From $(4,5,6,3)$ and (1) then we get:

$$
\begin{aligned}
& f(I, D)=k_{i} I+k_{x} D=f\left(I_{O}, D_{\circ}\right) \\
& M \frac{d^{2} D}{d t^{2}}=k_{i}\left(I-I_{\circ}\right)+k_{x}\left(D-D_{\circ}\right)
\end{aligned}
$$

The voltage equation of the electromagnetic coil is given by:

$$
\mathrm{V}(\mathrm{t})=\operatorname{Ri}(\mathrm{t})+\mathrm{L}(\mathrm{di} / \mathrm{dt})
$$

Now, taking Laplace transform and putting $\mathrm{mg}=-\mathrm{k}\left(\mathrm{I}_{\mathrm{o}} / \mathrm{D}_{\mathrm{O}}\right)$ then system:

$$
\mathrm{M} \frac{\mathrm{d}^{2} \mathrm{D}}{\mathrm{dt}^{2}}=\mathrm{k}_{\mathrm{i}}\left(\mathrm{I}-\mathrm{I}_{\mathrm{O}}\right)+\mathrm{k}_{\mathrm{z}}\left(\mathrm{D}-\mathrm{D}_{\mathrm{O}}\right)=\frac{2 \mathrm{kI}_{\mathrm{O}}}{\mathrm{D}_{\mathrm{O}}^{2}} \mathrm{I}-\frac{2 \mathrm{ki}_{\mathrm{O}}^{2}}{\mathrm{x}_{\mathrm{O}}^{3}}
$$




$$
\begin{gathered}
\mathrm{D}(\mathrm{s}) \mathrm{s}^{2}=\frac{2 \mathrm{kI} \mathrm{I}_{\circ}}{\mathrm{mD}_{\circ}^{2}} \mathrm{I}(\mathrm{s})-\frac{2 \mathrm{kI} \mathrm{I}_{\circ}^{2}}{\mathrm{mD}_{\circ}^{3}} \mathrm{D}(\mathrm{s}) \\
\frac{\mathrm{D}(\mathrm{s})}{\mathrm{I}(\mathrm{s})}=\frac{-1}{\mathrm{As}^{2}-\mathrm{B}}
\end{gathered}
$$

Where:

$\mathrm{A}=\mathrm{I}_{\mathrm{O}} / 2 \mathrm{G}$
$\mathrm{B}=\mathrm{I}_{\mathrm{O}} / \mathrm{D}_{\mathrm{o}}$

Define the input and output variables as $\mathrm{R}_{\mathrm{in}}, \mathrm{C}_{\mathrm{ou}}$ :

$$
G(s)=\frac{C_{\text {ou }}(s)}{R_{\text {in }}(s)}=\frac{k_{s} D(s)}{k_{a} I(s)}=\frac{-\left(\frac{k_{s}}{k_{a}}\right)}{A s^{2}-B}
$$

Then the system state variables are $\mathrm{x}_{1}=\mathrm{C}_{\text {out }} \mathrm{x}_{2}=\mathrm{C}_{\text {out }}$ and state equations are as:

$$
\left[\begin{array}{l}
\dot{x}_{1} \\
\dot{x}_{2}
\end{array}\right]=\left[\begin{array}{cc}
0 & 1 \\
\frac{2 \mathrm{G}}{\mathrm{D}_{\mathrm{O}}} & 0
\end{array}\right]\left[\begin{array}{l}
\mathrm{x}_{1} \\
\mathrm{x}_{2}
\end{array}\right]+\left[\begin{array}{c}
0 \\
-\frac{2 \mathrm{Gk}_{\mathrm{s}}}{\mathrm{I}_{\mathrm{O}} \mathrm{k}_{\mathrm{a}}}
\end{array}\right] \mathrm{C}_{\text {in }}
$$

The real data of magnetic levitation system are showed in Table 1, these parameter put in Eq. 14:

$$
\begin{aligned}
& {\left[\begin{array}{l}
\dot{x}_{1} \\
\dot{x}_{2}
\end{array}\right]=\left[\begin{array}{cc}
0 & 1 \\
6534 / 10 & 0
\end{array}\right]\left[\begin{array}{l}
\mathrm{x}_{1} \\
\mathrm{x}_{2}
\end{array}\right]+\left[\begin{array}{c}
0 \\
24991 / 10
\end{array}\right] \mathrm{C}_{\text {in }}} \\
& \mathrm{y}=\mathrm{x}_{1}
\end{aligned}
$$

After calculating the pole of system it is found that system has open loop poles on the left plane. Therefore, the GML system is unstable system.

The principle of interval type-2 fuzzy logic system: The principle of type-2 fuzzy logic have been introduced by Zadeh (1975) as concerning illustration a growth of a accepted Fluffy Set (FSs). type-2 fuzzy strategy are illustrated in multi research like (Williams, 2014) and (Kumar et al., 2012) but the foot of print uncertainty FOU was discussed in membership functions as (Williams, 2014). Foot print of uncertainty is used to process the uncertainty problem in real time application. type-2 fuzzy was consisted of several typl-fuzzy sets (Kumar et al., 2012). The response and control surface are worked with type-2 fuzzy by Khanesar et al. (2013). The main difference between type- 1 and 2 is third direction which named FOU. The grade form of type-2 fuzzy membership is $<1$ but a unity value when used the interval type-2 fuzzy (Ahmed and Petrov, 2015). Figure 3

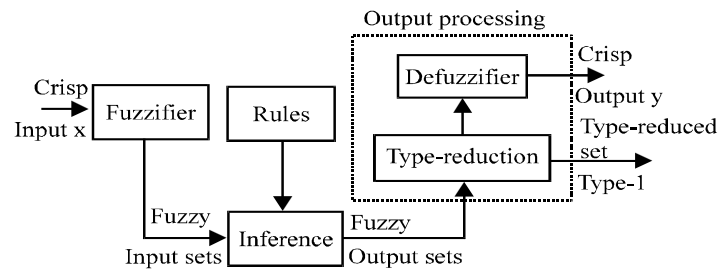

Fig. 3: Block digram of IT2FL controller

\begin{tabular}{llll}
\multicolumn{4}{l}{ Table 1: Real values of ML system parameters } \\
\hline Parameters & Symbols & Values & Units \\
\hline Mass & $\mathrm{M}$ & 0.022 & $\mathrm{~kg}$ \\
Constant & $\mathrm{K}_{\mathrm{a}}$ & 5.8929 & Unit less \\
Constant & $\mathrm{K}_{\mathrm{s}}$ & 458.7204 & Unit less \\
Current & $\mathrm{I}_{\mathrm{o}}$ & 0.6105 & $\mathrm{amp}$ \\
Distance & $\mathrm{D}_{\circ}$ & 0.03 & $\mathrm{~m}$ \\
Sphere radius & $\mathrm{R}$ & 0.0125 & $\mathrm{~m}$ \\
\hline
\end{tabular}

shows structure of IT2FL controller which consist of five blocks. The block diagram of reducer is used to minimized the type of output from fuzzy type 2-1 and represents the difference block between two types. Then, the output will be treat in defuzzifier block to produce the crisp output, then applied it to the system (ML). Four blocks are same in the fuzzy-1 (fuzzifier, rules, inference defuzzifier) and one block is differ from the fuzzy-1 (type-reducer) (Chaudhary et al., 2014; Khanesar et al., 2013). The crisp output is known as control action for plant to be handled for controlling and get good response.

Proposed controller design and implementation: The reason for designing of intelligent control like IT2FPID controller for magnetic levitation system that it will give exact positioning of steel sphere with no any mechanical help.

Interval type-2 fuzzy logic implementation: Interval type-2 fuzzy logic controller has been designed by create a MATLAB code program. Oscar castillo is designed a IT2FL controller by developed MATLAB toolbox (Londhe et al., 2016; Sain et al., 2016). Figure 4-6 illustrated the block diagram of IT2F PID controller. The controller block have been got two inputs, Change of Error (CE), Error (E) and one output, control action (u) which will feed to the $\mathrm{ML}$ system. The inference engine is used to create nonlinear mapping between $\mathrm{I} / \mathrm{O}$ of interval type-2 fuzzy logic controller (Toloue et al., 2015). Output of inference engine for type-2 fuzzy sets is processed by converting from type 2-1 via. type-reducer but output of inference engine for type-1 fuzzy directly feed to the defuzzifier. To acquire type-reducer sets is used augmentation of Zadeh. 


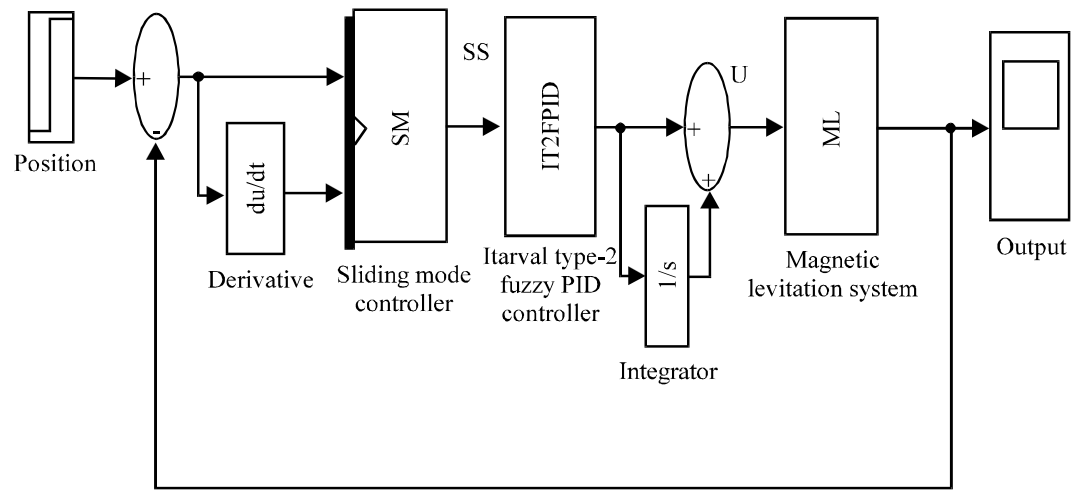

Fig. 4: Block diagram of IT2FPIDSM controller for ML system

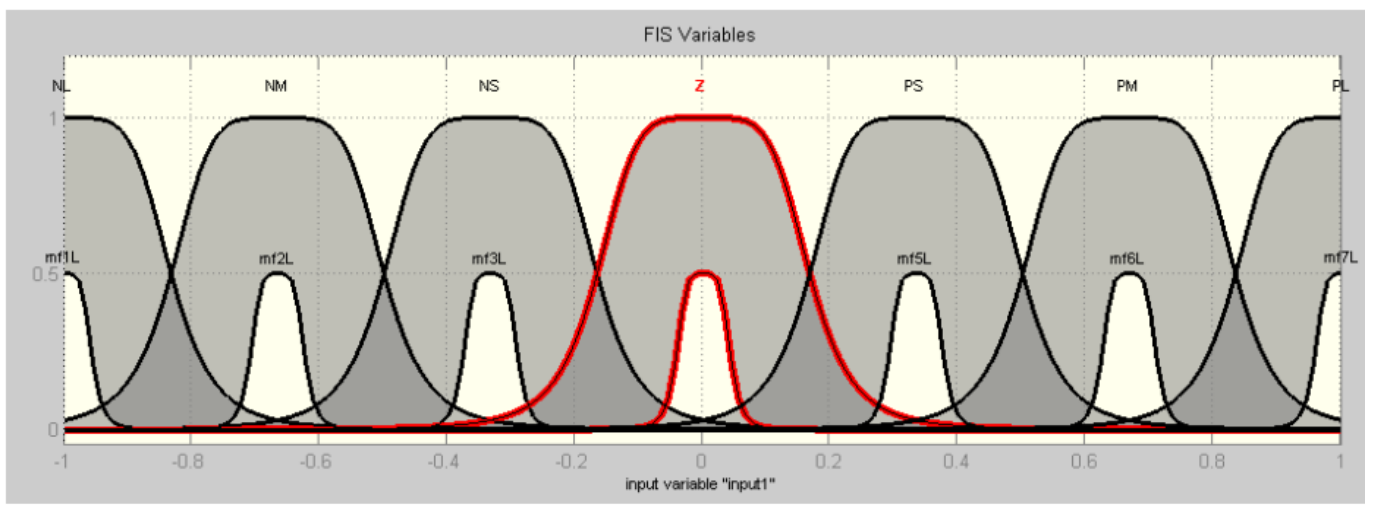

Fig. 5: Membership functions $\mathrm{I} / \mathrm{O}$ for sliding surface and control action

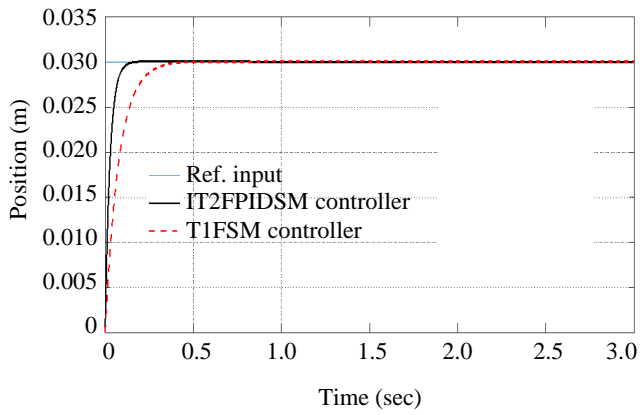

Fig. 6: Output response for IT2FSMC, TIFSMC

Table 2: Rule base for nominated IT2FPUDSM controller

\begin{tabular}{llllllll}
\hline E/CE & NL & NM & NS & Z & PS & PM & PL \\
\hline NL & NL & NL & NL & NL & NM & NS & Z \\
NM & NL & NL & NL & NM & NS & Z & PS \\
NS & NL & NL & NM & NS & Z & PS & PM \\
Z & NL & NM & NS & Z & PS & PM & PL \\
PS & NM & NS & Z & PS & PM & PL & PL \\
PM & NS & Z & PS & PM & PL & PL & PL \\
PL & Z & PS & PM & PL & PL & PL & PL \\
\hline
\end{tabular}

Design of IT2FPIDSM controller: Figure 7 shows the output responses for T1FPIDSM controller and others

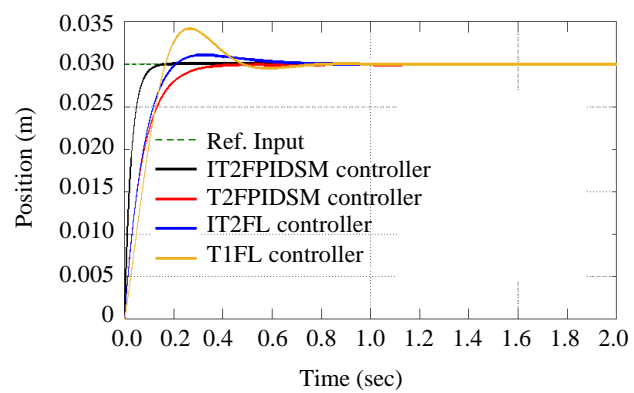

Fig. 7: Output responses of IT2FSMC, IT2FLC and T1FLC

after applied in $\mathrm{ML}$ system. When an occurrence of IT2FPIDSM controller The sliding mode is create to matching the dynamic behavior of the $\mathrm{ML}$ system and choose accurately the fuzzy rules. According to, Eq. 6 the multi inputs error and change of error convert to single input for fuzzy controller. The rule base in Table 2 is used to design IT2FL, T1FL and T1FSM controllers. A sliding surface is described as sum of product for slope and error with change of error (Fig. 5-7): 


Table 3: Reduced rule base for nominated IT2FPUDSM controller
\begin{tabular}{llllllll}
\hline SS & NL & NM & NS & Z & PS & PM & PL \\
\hline U & NL & NM & NS & Z & PS & PM & PL
\end{tabular}

$$
\mathrm{SS}=\mathrm{CE} . \mathfrak{£}+\mathrm{E}
$$

The slope of sliding surface must be positive and large than zero. The Membership Functions (MF) are illustrates in the Fig. 5 which it is consist of seven MF's and therefore, it is needed to forty nine rule bases according to the Eq. 8:

$$
\text { Rule }{ }^{i} \text { :IFSSis } \tilde{S}^{i} \text { Thenuis } \tilde{U}^{i}, \quad i=1,2, \ldots, 7
$$

where, $\tilde{\mathrm{s}}^{\mathrm{i}}$ and $\tilde{\mathrm{U}}^{\mathrm{i}}$ [NL NMNS Z PS PM PL] and $\tilde{\mathrm{s}}^{\mathrm{i}}, \tilde{\mathrm{U}}^{\mathrm{i}}$ are both interval type- 2 fuzzy set's. If the control operation is completed with IT2FPIDSM controller, the rules number decreases with continuous robustness for uncertainty and disturbances. The idea of this research can be summarized as:

Type-2 fuzzy like PID is the best choose to handle the nonlinearity in the $\mathrm{ML}$ system

- Using Social Spider Optimization (SSO) to find the optimum values of gains for input and output of fuzzy

- Reduced the rules which uses in controller process according to Table 2 and 3

- Position of state can be adjusted of control action required

- Wide or little control action according to close or far to the diag onal line of sliding surface

\section{RESULTS AND DISCUSSION}

The suggested IT2FPIDSM controller is applied to adjustment and control to the $\mathrm{ML}$ system and has been compared with T1FPIDSM controller according Fig. 7. The multi methods of controlling such as IT2FPIDSM, T1FPIDSM, IT2FLC and T1FLC are implemented for magnetic levitation system as Table 4 . Table 5 illustrate the response performances via. overshoot, rise time and settling time which is observed the zero overshoot and steady state error but very good settling time and rise time than others controllers.

The $\mathrm{ML}$ system performance tracking has been achieved by multireference trajectory. Sine wave trajectory is represented as the firstly, a varying reference point with several levels as the secondary. The sine wave trajectory is illustrated as (Fig. 8):

$$
\text { ref. }=\frac{[5+\sin (w t)]}{100}
$$

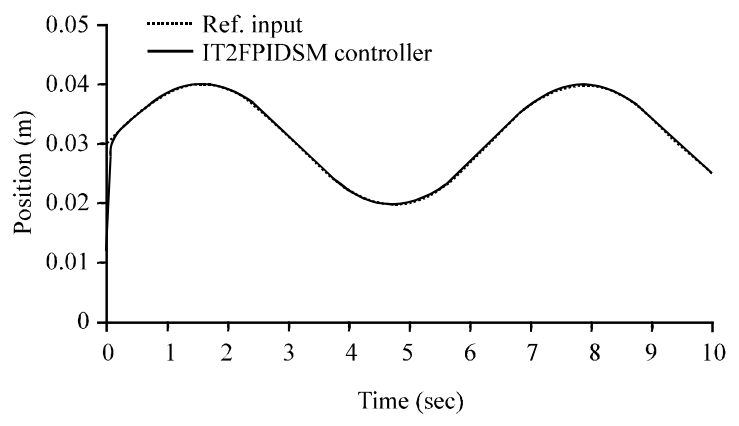

Fig. 8: The response of IT2FPDSM controller when input sine wave

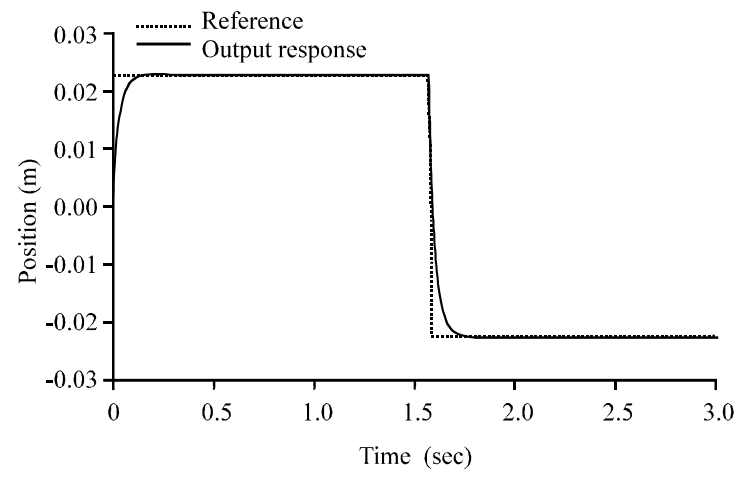

Fig. 9: The response of IT2FPIDSM controller with suddenly changing reference input

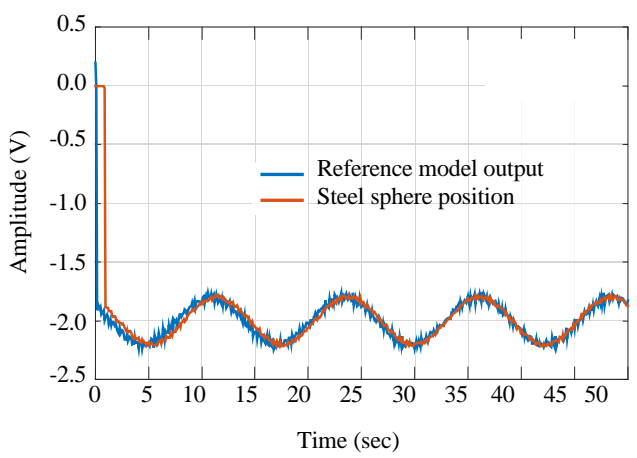

Fig. 10: Steel sphere position response with input reference is sine wave

The real-time control need these are a system which takes input reference and give output command through the simulation process.

The varying equilibrium position or another name the tracking to input reference through the Simulink MATLAB mission, getting the simulation results for $\mathrm{ML}$ system shown in Fig. 9 and 10. 
Table 4: Real model parameters

\begin{tabular}{ll}
\hline Physical parameters & Physical values \\
\hline $\mathrm{m}$ & $0.022(\mathrm{~g})$ \\
$\mathrm{N}$ & $2450(\mathrm{circles})$ \\
Iron core & $.22(\mathrm{~mm})$ \\
$\mathrm{K}_{\mathrm{f}}$ & 0.25 \\
$\mathrm{r}(\mathrm{b}$ all radius) & $12.5(\mathrm{~mm})$ \\
$\mathrm{R}$ & $13.8(\mathrm{o})$ \\
$\mathrm{X}_{0}$ & $0.03(\mathrm{~m})$ \\
Enameled wire diameter & $.0 .8(\mathrm{~mm})$ \\
$\mathrm{i}_{0}$ & $0.6105(\mathrm{~A})$ \\
$\mathrm{g}$ & $9.8\left(\mathrm{~m} / \mathrm{sec}^{2}\right)$ \\
$\mathrm{K}$ & $2.3142 \mathrm{e}-0.04\left(\mathrm{Nm}^{2} / \mathrm{A}^{2}\right)$ \\
\hline
\end{tabular}

Table 5: Numerical values for controllers performance

\begin{tabular}{lccc}
\hline Controller types & Overshoot $(\%)$ & Rise time $(\mathrm{sec})$ & Settling time (sec) \\
\hline IT2FSMC & 00.00 & 0.0626 & 0.1664 \\
T1FSMC & 00.00 & 0.1905 & 0.4789 \\
IT2FLC & 08.76 & 0.2000 & 0.5800 \\
T1FLC & 10.00 & 0.1980 & 0.6700
\end{tabular}

The robustness test has been achieved with a proposed controller. The comparison of transient responses for multi-controllers are applied. The better results are getting for type-2 fuzzy logic with a sliding mode like PID form than other. Figure 10 the simulation result of type-1 fuzzy logic is not acceptable because it has bad performance parameters. The effect of proposed controller in Fig. 10 is represented in adaptability when input test signal around -2 as reference steel sphere position for $\sin$ wave with $(2 / 10)$ as amplitude and $(1 / 10)$ as a frequency in Hertz. The output reference of $\mathrm{ML}$ system oscillates in airspace illustrate in Fig. 10.

Table 4, represents the zero maximum overshoot, very small settling time and zero steady state error for IT2FPIDSM controller.

\section{CONCLUSION}

Attractive levitation framework will be thick as mainstream test fittings in control research center to position control of the steel sphere. ML system is a nonlinear system with complex system parameters, unstable, light sensor and an electrical circuit to create the disturbances. ML system contains uncertainty, nonlinearity and miss position of steel sphere. type-2 fuzzy logic like PID has been creating and implemented with achievement to treat of some long-standing trouble. The output response of IT2FPIDSM controller for ML system is better when compared with all other controllers. Two types of test inputs have been used one is sine wave and other is a multi-level reference to check the responses tracking. IT2FPIDSM controller and T1FPIDSM controller not uses large computation and much processor complexity because of creating MATLAB code program and a minimum number of rule base and the proposed controller has enhanced output performance when compared to other controllers.

\section{REFERENCES}

Ahmed, S.A. and M.G. Petrov, 2015. Trajectory control of mobile robots using type-2 fuzzy-neural PID controller. IFAC. Pap. OnLine, 48: 138-143.

Chaudhary, H., A. Parashar, R. Prasad and N. Sukavanam, 2014. Velocity observer based fuzzy PDI based hybrid force/position control of an industrial robot. Proceedings of the 2014 International Conference on Recent Advances in Engineering and Computational Sciences (RAECS), March 6-8, 2014, IEEE, Chandigarh, India, pp: 1-6.

Corke, P., 2012. Robotics, Vision and Control: Fundamental Algorithms in MATLAB. Springer, Berlin, Germany, ISBN: 9783642201455, Pages: 570 .

Erguzel, T.T., 2013. Fuzzy controller parameter optimization using Genetic algorithm for a real time controlled system. Proceedings of the 2013 World Congress on Engineering Vol. 2, July 3-5, 2013, WCE, London, UK., ISBN:978-988-19252-8-2, pp: $3-5$.

Khanesar, M.A., E. Kayacan, O. Kaynak and W. Saeys, 2013. Sliding mode type-2 fuzzy control of robotic arm using ellipsoidal membership functions. Proceedings of the 2013 9th International Conference on Asian Control (ASCC), June 23-26, 2013, IEEE, Istanbul, Turkey, ISBN:978-1-4673-5767-8, pp: 1-6.

Kumar, A., M.K. Panda, S. Kundu and V. Kumar, 2012. Designing of an interval type-2 fuzzy logic controller for magnetic levitation system with reduced rule base. Proceedings of the 2012 3rd International Conference on Computing Communication and Networking Technologies (ICCCNT), July 26-28, 2012, IEEE, Coimbatore, India, pp: 1-8.

Londhe, P.S., Y. Singh, M. Santhakumar, B.M. Patre and L.M. Waghmare, 2016. Robust nonlinear PID-like fuzzy logic control of a planar parallel (2PRP-PPR) manipulator. ISA. Trans., 63: 218-232.

Mendel, J., H. Hagras, W.W. Tan, W.W. Melek and H. Ying, 2014. Introduction to type-2 Fuzzy Logic Control: Theory and Applications. John Wiley \& Sons, Hoboken, New Jersey, USA., ISBN:9781118901441, Pages: 376.

Nordin, F.H., F.H. Nagi and A.A.Z. Abidin, 2013. Comparison study of computational parameter values between LRN and NARX in identifying nonlinear systems. Turk. J. Electr. Eng. Comput. Sci., 21: 1151-1165. 
Sain, D., S.K. Swain and S.K. Mishra, 2016. TID and I-TD controller design for magnetic levitation system using Genetic algorithm. Perspect. Sci., 8: 370-373.

Shanmugasundram, R., K.M. Zakariah and N. Yadaiah, 2014. Implementation and performance analysis of digital controllers for brushless DC motor drives. IEEE. ASME. Trans. Mechatron., 19: 213-224.

Shen, H.Y. and L.C. Chang, 2013. Online multistep-ahead inundation depth forecasts by recurrent NARX networks. Hydrol. Earth Syst. Sci., 17: 935-945.

Siradjuddin, I., L. Behera, T.M. McGinnity and S. Coleman, 2014. Image-based visual servoing of a 7-DOF robot manipulator using an adaptive distributed fuzzy PD controller. IEEE. ASME. Trans. Mechatron., 19: 512-523.
Soto, R.M., O. Castillo, L.T. Aguilar and A. Rodriguez, 2015. A hybrid optimization method with PSO and GA to automatically design type- 1 and type- 2 fuzzy logic controllers. Intl. J. Mach. Learn. Cybern., 6: 175-169.

Toloue, S.F., M.R. Akbarzadeh, A. Akbarzadeh and M. Jalaeian-F, 2015. Position tracking of a 3-PSP parallel robot using dynamic growing interval type- 2 fuzzy neural control. Appl. Soft Comput., 37: 1-14.

Williams, B., 2014. An introduction to robotics. Mechanics and Controlof Robotic Manipulators. Mechanical Engineering, OhioUniversity, Athens, Ohio.

Zadeh, L.A., 1975. The concept of a linguistic variable and its application to approximate reasoning-I. Inform. Sci., 8: 199-249. 